Revista de Economia Política, vol. 28, $n^{\circ} 3$ (111), pp. 414-433, julho-setembro/2008

\title{
Inflação e deflação de ativos a partir do mercado imobiliário americano
}

\author{
MARIA CRISTINA PENIDO DE FREITAS \\ MARCOS ANTONIO MACEDO CINTRA*
}

Asset inflation and deflation triggered by the US housing financial system. This paper deals with the financial crisis triggered after the default of subprime mortgages in the United States which expanded to a global systemic crisis. It is divided into a brief introduction and three sections. The first section sums up the dynamics of inflation and deflation of real estate and financial assets which characterizes financeled cycles. The second section covers major effect of financial assets deflation on the American and European banks. The third section focuses on measures implemented by central banks in order to manage this financial crisis.

Keywords: subprime mortgages, financial innovations, financial crisis, asset inflation and deflation, role of central banks.

JEL Classification: E31; E32; G12; G21; G24.

"When the music stops, in terms of liquidity, things will get complicated. But as long as the music is playing, you've got to get up and dance. We're still dancing."

Chuck Prince III, ex-presidente do Citigroup

\section{INTRODUÇÃO}

O propósito deste artigo é discutir a crise no mercado de hipotecas subprime dos Estados Unidos que repercutiu fortemente no sistema bancário americano e europeu, configurando uma crise sistêmica. O espraiamento da crise, inicialmente

\footnotetext{
* Respectivamente, Professora do Departamento de Economia da PUC-SP, e-mail: crispenido@uol.com. br; Professor do Instituto de Economia da Unicamp e pesquisador do CNPq, e-mail: mamcintra@gmail. com. Submetido: Janeiro 2008; Aprovado: Fevereiro 2008.
} 
localizada em um mercado relativamente pequeno, tem suas raízes no processo de securitização dos créditos e no desenvolvimento de novos instrumentos e produtos financeiros, ${ }^{1} \mathrm{em}$ particular, dos derivativos de crédito, no qual os conglomerados financeiros desempenharam um papel crucial. O artigo está organizado em três seções, após esta breve introdução. Na primeira, procura-se realizar uma síntese da dinâmica dos processos de inflação e de deflação dos ativos mobiliários e financeiros, característicos dos ciclos finance-led. ${ }^{2} \mathrm{Na}$ segunda, examinam-se os impactos do processo de deflação de ativos no sistema bancário americano e europeu. $\mathrm{Na}$ terceira, analisam-se as decisões mais relevantes tomadas pelos bancos centrais a fim de gerir a crise financeira.

\section{DINÂMICA DA INFLAÇÃO E DA DEFLAÇÃO DOS ATIVOS AMERICANOS}

Até o início dos anos 1980, os bancos americanos mantinham em carteira até o vencimento os empréstimos que concediam. Embora algumas operações de crédito fossem vendidas uma a uma, como no caso dos empréstimos sindicados após a crise da dívida externa dos países em desenvolvimento em 1982, esse mercado era pequeno e ilíquido. Diante da maior ênfase das autoridades de regulamentação nos requisitos de liquidez e de capital — que culminou na elaboração do Acordo de Basiléia de 1988 e na definição de um coeficiente de capital mínimo de $8 \%$ dos ativos ponderados pelos riscos —, os bancos passaram a utilizar de forma crescente a securitização e os derivativos como instrumento de administração de balanço.

Assim, o processo de desregulamentação iniciado nos anos 1980 desmantelou a segmentação do sistema financeiro americano (Glass-Steagall Act, 1933, e McFadden Act, 1927), facilitando a conglomeração e o envolvimento dos bancos com o financiamento de posições nos mercados de capitais e em operações "fora de balanço". Nesse processo de formação dos full-service banking, bancos universais com diferentes linhas de negócio - varejo, investimento, seguro, gestão de ativos, gestão de fundo de pensão etc. - , emergem conglomerados financeiros menos dependentes das margens líquidas de juros, por meio de operações de empréstimos, como fonte de receitas e de lucros. ${ }^{3}$ Seus resultados dependem ca-

\footnotetext{
${ }^{1}$ Ver Aglietta (2004), Kregel (2007) e Guttmann \& Plihon (2008).

${ }^{2}$ Em função das limitações do escopo, não será efetuada uma abordagem teórica das inovações financeiras. Sugere-se, no entanto, que o trabalho tem como substrato teórico a análise de Minsky (1986) das modificações nas práticas monetárias e financeiras e seus impactos na dinâmica do sistema financeiro americano.

${ }^{3}$ Com a aprovação do Gramm-Leach-Bliley Financial Modernization Act (1999), generalizou-se a universalização das instituições bancárias ou "supermercados de serviços financeiros", mediante a formação de holding financeira. Sobre essas transformações, ver Coutinho \& Belluzzo (1996), Braga \& Cintra (2004) e Cintra \& Cagnin (2007).
} 
da vez mais de suas habilidade em gerar e transacionar ativos (compra e venda de moedas, commodities, títulos de dívidas soberanas e corporativas, hipotecas, ações, derivativos etc.), originando taxas, comissões e ganhos de capital. Os bancos tornaram-se "organizadores" ou "originadores" de ativos financeiros (cartão de crédito, empréstimos para compra de automóveis, hipotecas etc.), que são vendidos no mercado de capitais para instituições não-bancárias (fundos de pensão, companhias de seguro, fundos de investimento, hedge funds, fundos soberanos, private equity funds etc.).

Esse movimento esteve associado com avanços nos sistemas computacionais e na alocação de capital ponderada pelos riscos. Os sistemas computacionais facilitaram a precificação de inúmeros derivativos financeiros complexos (opções, derivativos de créditos e produtos estruturados) e a introdução dos modelos de scoring dos riscos (padrões de risco definidos por bancos de dados dos pagamentos e inadimplência dos devedores, perfil de renda, patrimônio dos tomadores).

Assim, o cerne do negócio bancário transformou-se da geração e carregamento de ativos, que geravam receita a partir dos spreads entre as taxas de juros, para geração e transação de ativos, atividades tradicionais de brokers e bancos de investimentos. Nesse movimento, o papel dos bancos no acompanhamento e avaliação da qualidade do crédito bem como no fornecimento da liquidez do sistema foi obnubilado.

Inspirados no modelo de transformação das hipotecas em ativos negociáveis (mortgage backed securities) da Government National Mortgage Association (Ginnie Mae) e das empresas patrocinadas pelo governo - Federal National Mortgage Association (Fannie Mae) e Federal Home Loan Mortgage Corp (Freddie Mac) -, os bancos desenvolveram novos instrumentos financeiros, os chamados produtos financeiros estruturados, que viabilizaram a constituição de um amplo mercado secundário para os empréstimos. Ao mesmo tempo, essas instituições passaram a priorizar operações não-registradas no balanço (garantias de crédito, por exemplo) e a criar diferentes tipos de empresas de propósitos especiais (SPV na sigla em inglês), como os veículos de investimento estruturados (SIV na sigla em inglês) e condutores externos (conduits). ${ }^{4}$ Os bancos transferiam parte de suas carteiras de crédito para esses veículos, em geral localizados em paraísos fiscais, de forma a reduzir as exigências de capital e liberar recursos para novos negócios.

Com o desenvolvimento de novos produtos e técnicas complexas de gestão e transferência de risco de crédito e com a proliferação de produtos financeiros estruturados, lastreados em diversos tipos de ativos de renda fixa e em recebíveis diversos, o processo de securitização atingiu o seu ápice (Quadro 1). De um lado, a exemplo dos bancos globais, os pequenos bancos regionais americanos, que concentravam suas operações de crédito nos mercados locais, passaram também a vender suas operações de crédito para seguradoras e hedge funds, transferindo

\footnotetext{
${ }^{4}$ O primeiro SIV foi criado pela filial do Citibank em Londres em 1988.
} 
os riscos de crédito e de mercado. As seguradoras conhecidas como monoline passaram a fornecer também garantias de retorno dos produtos estruturados. De outro lado, além reduzir o custo do endividamento para as famílias, empresas e governos, essas inovações financeiras, ao facilitar a avaliação e a precificação dos riscos, viabilizou a concessão de empréstimos para tomadores com fraco histórico de crédito, em particular, famílias de baixa renda.

\section{Quadro 1}

Produtos Financeiros Estruturados e Derivativos de Crédito

\begin{tabular}{|c|c|c|}
\hline $\begin{array}{c}\text { Ativos } \\
\text { Subjacentes }\end{array}$ & $\begin{array}{l}\text { Produtos } \\
\text { Financeiros } \\
\text { Estruturados }^{1}\end{array}$ & $\begin{array}{l}\text { Instrumentos de } \\
\text { Transferência dos } \\
\text { Riscos de Crédito }\end{array}$ \\
\hline $\begin{array}{l}\text { Crédito ao consumidor } \\
\text { (cartão de crédito), hipote- } \\
\text { cas residenciais, hipotecas } \\
\text { comerciais, empréstimos } \\
\text { para aquisição de veículos } \\
\text { e equipamentos. }\end{array}$ & $\begin{array}{l}\text { Asset-backed securities (ABS), } \\
\text { dentre os quais mortgage-backed } \\
\text { securities (MBS), que podem ser: } \\
\text { residential-mortgage-backed } \\
\text { securities (RMBS) e commercial } \\
\text { real estate-backed securities } \\
\text { (CREBS)/(CMBS) }\end{array}$ & \\
\hline $\begin{array}{l}\text { Títulos de dívida, negociá- } \\
\text { veis e não-negociáveis, de } \\
\text { empresas do setor privado } \\
\text { e de governos, produtos } \\
\text { estruturados, portfólios } \\
\text { híbridos. }\end{array}$ & $\begin{array}{l}\text { Asset-backed securities (ABS), } \\
\text { Collateralized loan obligation (CLO), } \\
\text { Collateralized bond obligation (CBO), } \\
\text { Collateralized debt obligation (CDO), } \\
\text { ABS CDO, CDO de CDO (CDO2), } \\
\text { Constant Proportion Debt Obliga- } \\
\text { tion (CPDO) }\end{array}$ & $\begin{array}{l}\text { Credit Default Swap } \\
\text { (CDS), CDO sintético } \\
\text { (CSO), CDS de ABS } \\
\text { (ABCDS). }\end{array}$ \\
\hline
\end{tabular}

Fonte: Parisi-Capone (2008), Partnoy \& Skeel Jr. (2006) e Fender \& Mitchell (2005). Elaboração própria. Nota': Alguns produtos estruturados também são derivativos de crédito, pois permitem em simultâneo a captação de recursos e a transferência de risco de crédito. Esses são os casos do CLO, CBO, ABS CDO, CDO do CDO e do CPDO.

Após a crise das ações das empresas de tecnologia (2000-2002), os bancos buscaram outros ativos para negociar. O boom nos preços dos imóveis tornou-se a alternativa para a geração de novas hipotecas, ampliação do crédito ao consumidor e extração de home equity por meio de refinanciamento de antigas hipotecas. Essas operações de refinanciamento permitiram as famílias converterem a valorização patrimonial de suas residências em poder de compra por meio do crédito. ${ }^{5}$ Assim, as famílias aumentaram seus níveis de endividamento, financiando a expansão dos investimentos imobiliários, puxando a economia americana rapidamente da recessão. E os conglomerados financeiros ampliaram suas taxas, comissões e receitas da administração de ativos.

Com a expansão da concessão de empréstimos imobiliários a tomadores de alto risco, os bancos fizeram uso intenso das transações não-registradas no ba-

\footnotetext{
${ }^{5}$ Para maiores detalhes sobre a extração de home equity por meio de refinanciamento, ver Cagnin (2007, pp. 73-74).
} 
lanço, transferindo aos SIV parte de suas carteiras de empréstimos subprime, de modo a evitar os requerimentos de capital associados a esses ativos. De acordo com FMI (2007, p. 18), as hipotecas subprimes representavam $25 \%$ dos ativos das SVI e $100 \%$ dos ativos das SVI lites, modalidade recente de SPE, que opera com alta alavancagem (40 a 70 vezes dependendo do colateral, segundo ParisiCapone, 2008).

Simultaneamente, proliferaram no mercado financeiro americano transações com instrumentos financeiros lastreados em hipotecas já securitizadas, tais como CDO, ABS CDO, CDO de CDO e CDO sobre CDO, emitidos pelos SIV e garantidos por linhas de crédito contingente fornecidas pelos bancos comerciais (Diagrama 1). Apenas em 2007, foram realizadas 307 emissões de CDO, com um volume total de US\$177,6 bilhões. Os grandes bancos atuaram ativamente na subscrição desses produtos financeiros estruturados. Cinco bancos - Merrill Lynch, Citi, UBS, Wachovia e Goldman Sachs - foram responsáveis por 53,5\% dessas transações, subscrevendo emissões no valor de US\$ 103 bilhões, ou seja, $58 \%$ do total (Oppenheimer, 2008, p. 11).

Embora tenham viabilizado a ampliação da liquidez no mercado de crédito e do endividamento de famílias, empresas e instituições financeiras, essas inovações financeiras potencializaram o risco de crise sistêmica. Isso porque, os contratos são amplamente interconectados, envolvendo diversos participantes e segmentos do mercado financeiro, configurando uma verdadeira pirâmide de crédito. Igualmente, afetaram a qualidade da avaliação e o monitoramento dos devedores pelas instituições originadoras dos empréstimos, pois essas ao transferir o risco de crédito deixam de realizar o monitoramento e acompanhamento efetivo do devedor.

Durante a euforia, hipotecas foram originadas e reempacotadas de diferentes formas - MBS, CDO - classificadas pelas agências de rating e revendidas. Nas $\mathrm{CDO}$, as hipotecas de diferentes riscos foram agregadas com recebíveis de cartão de crédito, recebíveis de empréstimos para a compra de automóveis, créditos corporativos, empréstimos para estudantes etc. Esses papéis - envolvendo recebíveis diversos com baixa correlação de risco - foram estruturados em várias tranches, de distintos graus de riscos classificados pelas agências de risco de crédito. Dessa forma, em um autêntico processo de alquimia, vários instrumentos financeiros de diversos riscos foram combinados pelas agências de rating e pelos emissores. As combinações foram realizadas de modo que alguns desses ativos lastreados em hipotecas subprime acabaram reclassificados como de excelente risco ou com grau de investimento.

O reempacotamento de hipotecas de alto risco, com a anuência das agências de classificação de risco de crédito, viabilizou suas aquisições pelos investidores com maior aversão ao risco. Assim, as tranches de menor risco - as Senior, classificadas entre A a AAA; as Mezzanine, classificadas entre BB a BBB - foram adquiridas pelos investidores institucionais. Uma parte importante desses créditos reempacotados foi exportada para fundos de investimentos da Coréia, Tawain, Austrália, China, França, Alemanha, Reino Unido etc. Diante do excesso de riqueza financeira acumulada (reservas internacionais dos asiáticos e dos exportadores 


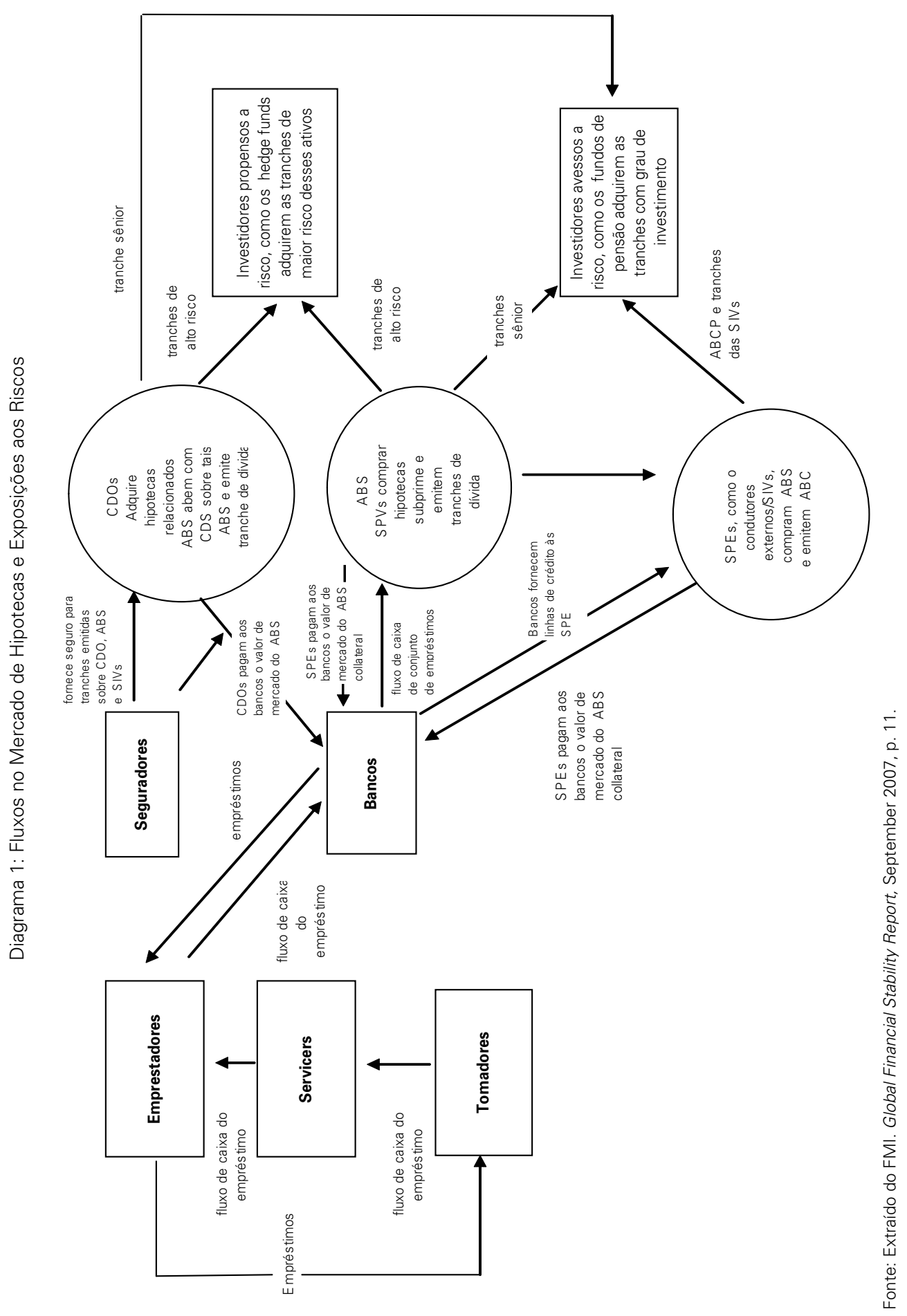


de petróleo) as mesas de operação dos bancos em Wall Street tinham ordens para adquirir qualquer dívida americana classificada com grau de investimento. As tranches de maior risco - denominadas Equities - foram transferidas para os hedge funds, por meio de operações alavancadas financiadas pelos próprios bancos. Nesse caso, o hedge fund investe, por exemplo, US\$ 10 para comprar US\$ 100 de tranches mais arriscadas de uma CDO e o banco securitizador financia os US\$ 90 restantes. Foram transformados também em componentes de novas emissões de $\mathrm{CDO}$ (CDO de CDO). Novamente, tranches foram criadas, a partir de notas emitidas pelas agências de classificação de risco, contendo resíduos altamente arriscados (Equities), em um processo sucessivo. Em alguns desses instrumentos foram agregados uma garantia de pagamento, seja pelo banco originador, seja por um derivativo de crédito (CDS subscrito por outro banco), seja pelas monolines.

Nesse processo foram gerados grandes volumes de tranches residuais altamente arriscadas - "resíduos tóxicos" no jargão dos investidores — difíceis de serem repassadas para outros investidores. Acabaram sendo transferidas para os SIV. Para carregar esses papéis, os SIV emitiram ABCP, dívida de curto prazo lastreada em ativos (CDO, classificada como Equity), contando com uma linha de crédito contingente fornecida pelas instituições financeira controladora para garantir a liquidez dos papéis. Inicialmente, essa gestão arriscada dos "resíduos tóxicos" - dívida de longo prazo sendo financiada com papéis de curto prazo permitia ganhos extraordinários proveniente das diferenças entre as taxas de juros dos dois mercados. Esse spread foi ainda ampliado por meio da alavancagem no mercado de commercial papers (alguns chegaram a alavancar em até 70 vezes o capital). Com a elevação das taxas de juros de curto prazo nos EUA, a liquidez excessiva forçou a queda das taxas de juros longas, reduzindo esses spreads e a rentabilidade dessas operações.

Por um lado, esses produtos estruturados não dispunham de mercados líquidos, o que dificultava a formação de um preço de mercado. Por outro lado, diante da inexistência de observações empíricas sobre o comportamento desses novos instrumentos financeiros, os modelos de precificação dos riscos foram constituídos por séries históricas de default para os diferentes ativos (não-correlacionados) embutidos na CDO, por exemplo. No ambiente de euforia e ampla liquidez, CDO contendo hipotecas subprime, sem séries estatísticas disponíveis, geraram tranches Senior, com grau de investimento, em uma clara indicação de subavaliação dos riscos e de sobreavaliação de ganhos potenciais.

Com um mercado em expansão, a capacidade desses produtos complexos e opacos encontrar compradores ampliou a confiança e reduziu a aversão ao risco dos bancos (originadores), dos investidores (carregadores) e das famílias (tomadoras). Bancos, companhias financeiras e instituições independentes, originadores de hipotecas, passaram a oferecer produtos mais atrativos (maiores rendimentos), mas reduzindo os padrões de avaliação e da qualidade das hipotecas não-conformes (não garantidas pelas agências federais - Fannie Mae, Ginnie Mae e Freddy $\mathrm{Mac})$. A concorrência entre os agentes financeiros levou à proliferação do uso de diferentes tipos de contrato de maneira a atrair os tomadores de maior risco 
(e maior rendimento). Dessa forma, reduziram os padrões de subscrição e ofereceram uma série de contrato, tais como as balloon mortgage ou interest-only loan (neste contrato, em um período são pagos apenas os juros, após este período, além dos juros deverá também ocorrer a amortização do principal) e as hipotecas híbridas, que combinam o pagamento de taxas prefixadas no início do contrato e depois se tornam contratos pós-fixados. Grande parte das hipotecas subprime emitidas entre 2004 e 2006 era risk-layered, combinando vários atrativos para tornar a operação mais interessante e, conseqüentemente, mais arriscada (Cintra \& Cagnin, 2007).

As carteiras de crédito imobiliário eram rapidamente securitizadas. De um lado, as receitas dos bancos, de instituições independentes e das agências de rating expandiam. De outro lado, uma fragilidade financeira crescente era gestada no interior do sistema. As instituições independentes e as companhias financeiras passaram a tomar empréstimos dos bancos para originar hipotecas não-conformes. Os empréstimos eram pagos com a securitização das hipotecas. Em suma, com os preços dos imóveis em alta, novas hipotecas eram geradas, realimentando a expansão e a valorização dos ativos imobiliários. Os elevados preços dos imóveis validavam a sobreavaliação das tranches Senior e produziam elevados retornos para as tranches residuais. Hipotecas e instrumentos financeiros cada vez mais arriscados eram espalhados pelo sistema financeiro global. O papel das agências de rating foi crucial no processo de arbitragem dos riscos e rentabilidade dos créditos que está na base da securitização estruturada.

A dinâmica de funcionamento dos SIV tornou-se bastante semelhante a de um pequeno banco comercial: passou a realizar empréstimos de longo prazo com passivos de curto prazo, em um processo clássico de desequilíbrio de prazos, sem regulamentação e supervisão (Kregel, 2007, p. 23). Todavia, há diferenças importantes do ponto de vista da fragilidade financeira. Bancos comerciais criam depósitos e têm acesso direto às reservas do banco central. No SIV a capacidade de criar liquidez está ausente. Assim, a estabilidade e liquidez dos SIV dependem da liquidez bancária. Num momento de turbulência, os ativos transferidos para os SIV precisam ser vendidos, refinanciados pelos bancos (substituição do commercial paper por empréstimos) ou retornar para o balanço dos bancos, dada a linha de crédito stand-by existente entre eles. Isso significa que se os commercial papers não forem renovados, o banco terá de fazer um empréstimo ou trazer os ativos para seu balanço, o que exigirá a elevação do capital.

A partir de meados de 2006, o mercado imobiliário americano passou a emitir sinais de encolhimento, nos preços e nas quantidades. Além disso, começou a se explicitar, nos termos de Minsky (1986), a fragilidade das estruturas financeiras, com elevado risco e baixa capacidade de fornecer liquidez, dada a utilização crescente das instituições afiliadas (SIV, fundos de investimento, seguradoras etc.). Seu funcionamento dependia do aumento dos preços dos imóveis, do fluxo de novas hipotecas e da queda das taxas de juros. A partir de fevereiro de 2007, uma cadeia de eventos começou a revelar a fragilidade dos instrumentos e das estruturas financeiras: inadimplência das famílias subprime, com hipotecas com taxas de juros 
ajustadas ou flutuantes, execução de devedores inadimplentes, quedas nos preços dos imóveis, movimentos de saques em hedge funds, rebaixamento das notas de alguns produtos estruturados. "Senior securities quickly transformed into the value of their underlying subprime collateral" (Kregel, 2008, p. 19). Investidores institucionais, sujeitos às regras de prudência, e que carregaram apenas ativos com grau de investimento, foram forçados a vender os ativos rebaixados. Seguradoras monolines e outros agentes de seguro de crédito, e investidores aumentaram as vendas de hipotecas subprime, derrubando seus preços. O processo de inadimplência e deflação de preços alcançou os produtos estruturados e os SIV. Estima-se que a exposição de risco dos bancos globais no mercado de ABCP havia ultrapassado os US\$ 900 bilhões (Kregel, 2007, p. 25).

A incerteza sobre o valor dos ativos que lastreavam esses papéis levou a um dramático declínio no estoque e uma elevação na taxa de juros na Europa e nos EUA, produzindo uma crise de liquidez. Para evitar o default (ou a completa liquidação dos portfólios), os bancos foram forçados a garantir as linhas de crédito de contingência. Assim, ativos, que os bancos haviam retirado de seus balanços, voltaram no momento em que foram chamados a fornecer liquidez para os SIV. Nesse processo, muitos bancos tiveram de captar novos recursos para elevar o capital ponderado pelos riscos, sobretudo, de fundos soberanos.

No final de fevereiro e início de março de 2008, os bancos começaram também a exigir depósitos de margens mais altos para refletir os novos preços dos ativos. ${ }^{6}$ Como sugerido, os hedge funds e outros investidores altamente alavancados tomam recursos de um financiador, dando como garantia ativos de suas carteiras, quando o valor dos ativos cai, a alavancagem sobe e pode ultrapassar o limite estabelecido pelo financiador que exige sua diminuição pela venda dos ativos ou por aumento da margem. As vendas compulsórias, para se readequar às regras do financiamento da alavancagem, conduzem ao aumento da volatilidade que é retransmitido para outros mercados. A desvalorização dos preços força outros fundos a reconhecerem perdas porque obrigados a registrar o valor dos ativos no nível das negociações que ocorrem no mercado, por meio da marcação a mercado, incentivando outros investidores a também resgatarem suas cotas. Isso pode levar a círculos viciosos de vendas forçadas de ativos, bem como de aumento de taxas de juros em vários mercados (para viabilizar as chamadas de margens).

Os bancos ainda carregam derivativos de crédito - cujo valor nocional total foi estimado em US\$ 75 trilhões - de hipotecas subprimes e produtos estruturados. O mesmo ocorre com muitas seguradoras, que garantem as emissões de bônus de Estados e Municípios americanos, um mercado de US\$ 2,2 trilhões. Essas seguradoras podem ter seus ratings, que se transferem para os títulos garantidos, rebaixados. O rebaixamento dos títulos poderá forçar a sua revenda pelos inves-

\footnotetext{
${ }^{6}$ Segundo o JP Morgan Chase: “Wall Street banks are facing a 'systemic margin call' that may deplete banks of $\$ 325$ billion of capital due to deteriorating subprime U.S. mortgages" (Reuters, March 8 2008).
} 
tidores que podem carregar apenas ativos classificados como grau de investimento, possibilitando nova fonte de deflação nos preços dos ativos. As seguradoras monoline, por sua vez, terão de honrar as obrigações de imóveis cujos preços declinam e as taxas de inadimplência aumentam. ${ }^{7}$ Como o valor dos produtos estruturados tende a convergir para o valor do ativo subjacente, em alguns casos pode se aproximar de zero, ampliando as perdas deste segmento (Kregel, 2008, p. 20). Roubini (2008) estimou que, em março de 2008, havia cerca de 8 milhões de famílias com valor da dívida superior ao valor do imóvel nos EUA. Parece plausível supor que inúmeras dessas famílias irão abandonar o imóvel e a hipoteca, transferindo o problema para o credor, um banco ou um investidor. Enfim, a crise toma dimensões clássicas de um processo de deflação de ativos, em que posições devem ser vendidas para honrar os compromissos - pagar os agentes financeiros e os saques dos investidores (Minsky, 1986). ${ }^{8}$

Esse movimento ocorre em um mercado ilíquido. Os compradores de ativos - hipotecas, créditos corporativos, produtos estruturados, derivativos - desaparecem do mercado no exato momento em que a crise de iliquidez provoca, em muitas instituições, a necessidade de vendê-los para se fazer caixa (atender chamadas de margem e efetuar resgates dos investidores). Os preços dos ativos caem. Nesse contexto torna praticamente impossível identificar o valor de determinados ativos nas carteiras das instituições (sobretudo dos mais complexos e pouco negociados) e os agentes econômicos procuram refúgio nos títulos públicos de maior segurança do mercado.

\section{OS PREJUÍZOS DOS BANCOS E A CONTRAÇÃO DO CRÉDITO}

Dada a integração dos diferentes segmentos dos mercados, a crise iniciada no mercado subprime foi se espraiando rapidamente para os diversos segmentos do mercado financeiro tanto americano como global. Em um cenário de forte incerteza em relação ao risco de contraparte, os bancos passaram a exercer preferência pela liquidez, contraindo os empréstimos no mercado interbancário. Igualmente, reduziram a concessão de crédito aos clientes, mesmo os de excelente risco.

Com a deterioração dos empréstimos imobiliários de alto risco, as agências de rating rebaixaram a classificação de centenas de títulos relacionados às hipotecas subprime, contribuindo para ampliar a incerteza em relação aos produtos financeiros estruturados. Com a crise, os métodos de avaliação dessas agências

\footnotetext{
${ }^{7}$ Comprometidas com o mercado de hipoteca subprime, as seguradoras, Ambac Financial Group e MBIA, contabilizaram grandes perdas no último trimestre de 2007 (US\$ 8,5 bilhões), com a elevação da inadimplência e do rebaixamento da classificação de inúmeras CDO. Com a divulgação desses resultados, essas seguradoras enfrentaram queda na cotação de suas ações e/ou rebaixamento de sua classificação de risco.

${ }^{8}$ Segundo o Bank of America, US\$ 7,7 trilhões evaporaram dos mercados acionários dos quatro cantos do mundo entre outubro de 2007 e janeiro de 2008.
} 
começaram a ser questionados pelas autoridades européias e americanas. Sobretudo, porque há um nítido conflito de interesse envolvido nas classificações de risco, já que quase $50 \%$ das receitas das agências provêem do rating desses complexos instrumentos financeiros estruturados e subscritos pelos bancos. ${ }^{9}$

Dúvidas crescentes sobre o grau de exposição dos bancos à crise das hipotecas subprime provocaram o empoçamento de liquidez no mercado interbancário. A desconfiança também contaminou o mercado de $\mathrm{ABCP}$, ocasionando problemas de iliquidez em várias instituições americanas e européias.

A contração do crédito se aprofundou ainda mais com os rumores de que a Countrywide - maior empresa americana de hipotecas e pioneira do segmento de subprime - teria utilizado integralmente os US\$ 11,5 bilhões de suas linhas de crédito stand-by. Duramente atingida pela credit crunch e pelo aumento da inadimplência, essa empresa acabou sendo adquirida pelo Bank of America por US\$ 4 bilhões em janeiro de 2008, após a queda de $48 \%$ em suas ações na Bolsa de Nova York (The Economist, 2008).

Do outro lado do Atlântico, a crise no mercado americano de crédito subprime atingiu direta e indiretamente alguns bancos. Em agosto, o pequeno banco do Estado alemão da Saxônia, Sachsen Landesbank, após receber aporte de US\$ 23 bilhões para cobrir perdas com ativos lastreados em empréstimos habitacionais americanos, foi vendido ao maior banco público regional, o Landesbank BadenWürttemberg por US\$ 409 milhões. Os problemas do Sachsen LB repercutiram no terceiro maior banco inglês, o Barclays, cujas ações caíram no final de agosto depois que o Financial Times informou que sua exposição ao mercado de hipoteca subprime seriam de centenas de milhões de dólares. Isto porque, além de conceder linha de crédito a quatro SIV criados pela sua subsidiária Barclays Capital, o banco criou um SIV em nome do Sachsen LB em maio, ou seja, três meses antes da quebra deste, com ativos avaliados em US\$ 3 bilhões, investidos, em grande parte, em títulos lastreados por hipotecas americanas normais e subprime.

No início de setembro de 2007, outro banco alemão, o IKB, quase foi à falência, devido aos seus investimentos em ativos de crédito estruturado, que incluíam exposição a empréstimos subprime. Para evitar o colapso do IKB, o banco central alemão coordenou uma operação de resgate junto aos grandes bancos domésticos. Nessa operação, o IKB recebeu aporte de $€ 8,1$ bilhões do banco de fomento KfW (que já possuía uma participação de $38 \%$ no IKB) e outros $€ 6,1$ bilhões em linhas de crédito de um grupo de bancos.

Nos meses de setembro e outubro, novos anúncios de aprovisionamento contábil para cobrir eventuais perdas associadas ao mercado de hipotecas subprimes se sucederam, contribuindo para aumentar a volatilidade dos preços dos ativos nos mercados globais. Grandes bancos admitiram prejuízo maior do que o estimado pelos analistas e/ou divulgado anteriormente pelos seus executivos. Esse

\footnotetext{
${ }^{9}$ Esse problema de conflito de interesse na ação das agências de risco vem sendo ressaltado na literatura há alguns anos. Ver Farhi \& Cintra (2002) e Fender \& Mitchell (2005).
} 
foi o caso do Citigroup que, após revelar perda de US\$ 3,1 bilhões, efetuou baixa contábil de US\$ 8,7 bilhões no seu balanço trimestral. O mesmo ocorreu com a Merrill Lynch, cujas perdas contábeis no terceiro trimestre associadas às hipotecas subprime foram de US\$ 7,9 bilhões, ao invés de US\$ 5,6 bilhões divulgado pelo seu executivo, Stan O’Neal.

Também contabilizaram perdas com transações relacionadas ao mercado subprime em seus balanços no terceiro trimestre, outros bancos americanos e europeus, como o UBS, Deutsche Bank, Bank of America, JP Morgan, Bear Stearns, Lehman Brothers, HSBC, Morgan Stanley, Wachovia, Barclays, Crédit Suisse, Royal Bank of Scotland, e o japonês Nomura Securities. Esse que é um dos principais bancos de investimento do Japão anunciou em outubro o encerramento de suas atividades no mercado de hipotecas subprime, após incorrer em prejuízo de US\$ 621 milhões. Também os bancos canadenses - CIBC, NBC, BMO e RBC - se envolveram com mercado subprime americano, assumindo posições em CDO que se traduziram em pesadas perdas já contabilizadas.

Igualmente, as agências patrocinadas pelo governo, Fannie Mae e Freddie Mac, que respondem, diretamente ou com garantia, por quase metade dos US\$ 10,5 trilhões do estoque de empréstimos imobiliários residenciais, divulgaram perdas, respectivamente, de US\$ 1,4 bilhão e US\$ 2 bilhões. Embora, ao contrário dos bancos, não tenham se envolvido com os complexos e problemáticos CDO, essas agências adquiram títulos vinculados a hipotecas com taxas de juros ajustáveis realizadas com tomadores de baixa renda. Em 2006, esses títulos representavam $20 \%$ dos novos negócios realizados pelo Freddie Mac.

No início de janeiro de 2008, os bancos começaram a divulgar os seus resultados contábeis do quarto trimestre de 2007 , ruins como já era mais ou menos esperado. Maior banco do mundo por volume de ativos, o Citi incorreu em prejuízo de US\$ 9,8 bilhões no quarto trimestre, em razão da redução de US\$ 18,1 bilhões no valor dos títulos de crédito subprime e CDO. No ano, contudo, o Citi teve lucro de US\$ 3,62 bilhões, $83 \%$ inferior ao de 2006. Ao mesmo tempo, o banco registrou no balanço US\$ 49 bilhões em títulos lastreados em dívida subprimes, fechando sete de seus SIV, que enfrentavam dificuldade de captar no mercado monetário.

Até o dia 18 de janeiro de 2008, considerando os balanços já divulgados do quarto trimestre, as perdas contabilizadas pelos bancos comerciais e de investimento montavam, aproximadamente, a US\$ 140 bilhões. Porém, as estimativas efetuadas pelos analistas de investimento dos próprios bancos indicavam que os prejuízos poderão superar US\$ 430 bilhões. Além dos produtos estruturados em carteira, são grandes os volumes de empréstimos habitacionais concedidos com taxas ajustáveis que podem se tornar inadimplentes. Adicionalmente, os bancos começaram a enfrentar problemas de inadimplência em crédito pessoal, como cartão de crédito, e financiamento a veículos, operações que também são utilizadas como ativos subjacentes do processo de securitização.

Dentre os bancos europeus que já divulgaram o balanço de 2007, as perdas mais expressivas relacionadas ao mercado subprime foram registradas pelos ban- 
cos britânicos, suíços, alemães e franceses. Até meados de fevereiro, as perdas contábeis anunciadas totalizavam US\$ 36 bilhões. Porém, a crise não atingiu a todos com o mesmo grau de intensidade. $\mathrm{O}$ banco europeu com maior exposição à crise subprime foi o suíço UBS, que registrou seu primeiro prejuízo anual em uma década. Já o seu rival Crédit Suisse apresentou resultado positivo, apesar de perdas contábeis de US\$1,8 bilhão com CDO e hipotecas residenciais.

$\mathrm{Na}$ Alemanha, além dos grandes bancos privados, contabilizaram depreciação de ativos bancos públicos regionais, como IKB, Sachsen LB e o WestLB. Esse último, além de registrar perdas contábeis de quase US\$1,5 bilhão, anunciou em prejuízo anual de US\$ 1 bilhão. Já os dois maiores bancos alemães, o Deutsche Bank e Commerzabank, registraram lucros recordes em 2007, a despeito das desvalorizações dos ativos relacionadas às hipotecas subprime. O Deutsche registrou no ano lucro de US\$ 9,4 bilhões, 7\% maior do que o de 2006, enquanto o Commerzabank anunciou lucro anual de US\$ 2,7 bilhões, 19,5\% superior ao registrando em 2006, mesmo tendo contabilizado perdas da ordem de US\$ 1,1 bilhão nos três últimos trimestres de 2007.

Os principais bancos americanos e grandes bancos europeus concederam linhas de crédito stand-by para as emissões de commercial papers pelos SIV, que assumiram seus ativos subprime. Como mencionado, os bancos tiveram de honrar esse crédito, o que implicou registro contábil e necessidade de atender rapidamente os requerimentos de capital. Para atender às exigências regulatórias, os bancos foram buscar aportes de capital junto aos investidores estrangeiros, e, em particular, junto aos fundos soberanos dos países em desenvolvimento superavitários.

Em novembro de 2007, por exemplo, o fundo soberano de Abu Dhabi adquiriu participação de 4,9\% no capital do Citi, aportando US\$ 7,5 bilhões, enquanto o Temasek, um dos fundos soberanos de Cingapura, investiu US\$ 4,4 bilhões na Merrill Lynch. Em dezembro, também o banco suíço UBS recebeu aporte de capital da ordem de US\$ 15,6 bilhões, vendendo participação acionária a investidores estrangeiros, como o fundo soberano GIC de Cingapura (Tabela 1). No total, os bancos comerciais e de investimento mais afetados com a crise das subprimes reforçaram o capital com a captação de US\$ 71,5 bilhões entre outubro de 2007 e janeiro de 2008.

As repercussões da crise das hipotecas suprime no mercado financeiro global mostraram que, a despeito do intenso processo de securitização e conseqüente ampliação do mercado de capitais, os bancos mantiveram seu papel-chave de fornecedores de liquidez para o conjunto da economia, inclusive o mercado financeiro. Com o aumento da incerteza sobre a magnitude das perdas e o grau de exposição de cada contraparte, os bancos passaram a exercer a preferência pela liquidez e a contrair crédito tanto no mercado interbancário como para os clientes. 
Tabela 1: Levantamento de Capital por Grandes Bancos Comerciais e de Investimento (out.2007 a jan.2008)

\begin{tabular}{|c|c|c|c|c|}
\hline $\begin{array}{l}\text { Data do } \\
\text { Anúncio }\end{array}$ & $\begin{array}{l}\text { Instituição } \\
\text { Financeira }\end{array}$ & $\begin{array}{c}\text { Fonte } \\
\text { de Recurso }\end{array}$ & $\begin{array}{c}\text { Tipo de } \\
\text { Instrumento }\end{array}$ & $\begin{array}{l}\text { Volume } \\
\text { (US\$ bi.) }\end{array}$ \\
\hline 23/10/2007 & $\begin{array}{l}\text { Bear } \\
\text { Stearns }\end{array}$ & Citic Securities & $\begin{array}{l}\text { Títulos preferenciais } \\
\text { conversíveis }\end{array}$ & 1,0 \\
\hline $26 / 11 / 2007$ & Citibank & Abu Dhabi Investment Authority & Ações ordinárias & 7,5 \\
\hline 10/12/2007 & UBS & $\begin{array}{l}\text { Government of Singapore } \\
\text { Investment Corporation, } \\
\text { investidor não revelado do } \\
\text { Oriente Médio e investidores } \\
\text { públicos }\end{array}$ & $\begin{array}{l}\text { Novas ações ordinárias } \\
\text { e troca de ações }\end{array}$ & 15,6 \\
\hline 19/12/2007 & $\begin{array}{l}\text { Morgan } \\
\text { Stanley }\end{array}$ & China Investment Corporation & Ações ordinárias & 5,0 \\
\hline $24 / 12 / 2007$ & Merill Lynch & Temasek; Davis Select Advisors & Ações ordinárias & 6,2 \\
\hline 15/01/2008 & Citibank & $\begin{array}{l}\text { Government of Singapore } \\
\text { Investment Corporation e outros } \\
\text { investidores públicos e privados }\end{array}$ & Ações ordinárias & 14,5 \\
\hline 15/01/2008 & $\begin{array}{l}\text { Merill } \\
\text { Lynch }\end{array}$ & $\begin{array}{l}\text { Korean Investment Corporation } \\
\text { Kuwait Investment Authority } \\
\text { Mizuho e outros }\end{array}$ & $\begin{array}{l}\text { Títulos preferenciais } \\
\text { conversíveis } \\
\text { e não-conversíveis }\end{array}$ & 6,6 \\
\hline $22 / 01 / 2008$ & Wachovia & Oferta pública & $\begin{array}{l}\text { Ações preferenciais } \\
\text { e trust preferenciais }\end{array}$ & 3,1 \\
\hline $21 / 01 / 2008$ & $\begin{array}{l}\text { Bank of } \\
\text { America }\end{array}$ & Oferta pública & $\begin{array}{l}\text { Títulos perpétuos } \\
\text { conversíveis em ações } \\
\text { preferenciais }\end{array}$ & 12,9 \\
\hline Total & & & & 71,5 \\
\hline
\end{tabular}

Fonte: Extraído de Oppenheimer - Industry Up to Date, 29 de janeiro de 2008, p. 6.

\section{GESTÃO DA CRISE}

A virtual paralisia do mercado de $A B C P$ e os sucessivos anúncios de contabilização de perdas com ativos lastreados em hipotecas ocasionaram uma dramática iliquidez nos mercados interbancários, expressa na forte volatilidade da fed funds rate e do TED spread - diferença entre a taxa dos títulos do Tesouro americano de três meses e a dos depósitos em eurodólar de três meses, considerada indicador de risco sistêmico (Gráfico 1). Essa situação exigiu a pronta intervenção dos bancos centrais, sobretudo, o Fed e o Banco Central Europeu (BCE), que injetaram US\$ 3,2 trilhões nos mercados monetários entre os dias 27 de julho e 12 de setembro de 2007. 
Gráfico 1

Evolução dos Prêmios de Risco no Mercado Interbancário na Europa (\%)

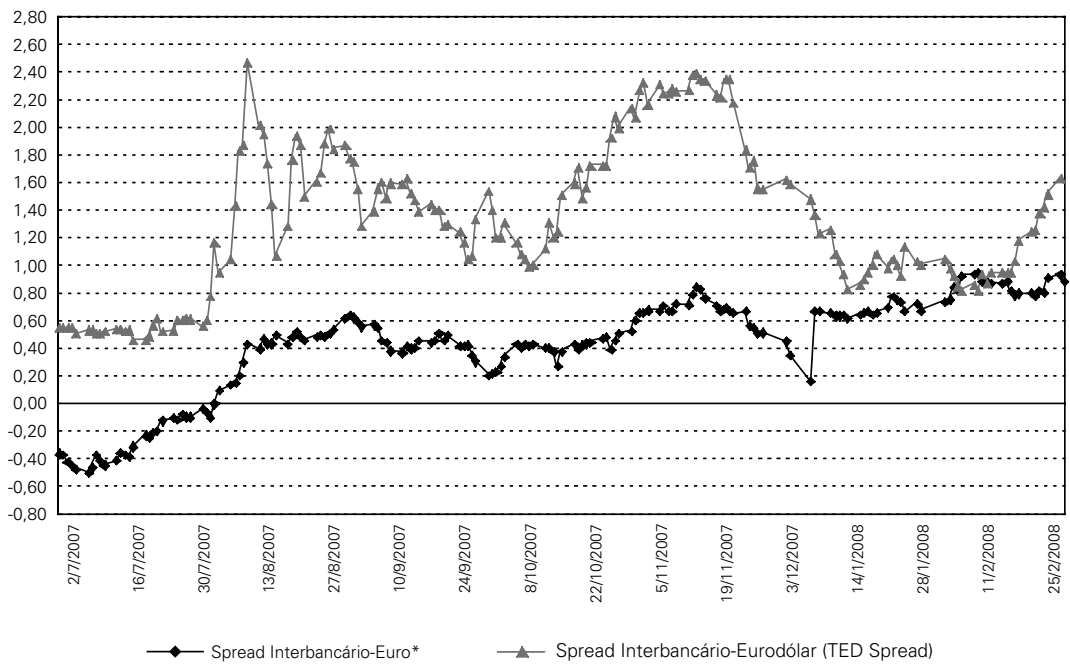

Fonte: British Bankers' Association e página eletrônica do Federal Reserve e do Bundesbank. Nota*: O spread do mercado interbancário em euro foi calculado pela diferença da taxa Libor de depósito de três meses em euro e os bônus do governo federal alemão.

Embora essas ações tenham acalmado temporariamente os mercados, promovendo a redução das taxas de juros interbancárias a um nível mais adequado, não tiveram o efeito de conter o aprofundamento da crise, em razão da dimensão da pirâmide de crédito construída em cima dos empréstimos de hipotecas de alto risco. A iliquidez exigiu ainda a entrada dos Bancos Federal Home Loan Banks, sistema composto por doze bancos regionais, que ofertaram enormes volumes de recursos ao mercado, contra garantias de créditos imobiliários.

$\mathrm{Na}$ atuação dos principais bancos centrais nota-se, contudo, diferenças de $t i$ ming e de estratégia de enfrentamento da crise. Tão logo percebeu a gravidade da crise, tardiamente na avaliação de alguns analistas, e a ameaça de forte desaceleração da economia, em setembro, o Fed deu início a flexibilização da política monetária. Já o Banco da Inglaterra preso ao seu mandato de guardião da estabilidade dos preços só decidiu pela redução da taxa básica de juros no dia 6 de dezembro, quando efetuou um corte de apenas 0,25 pontos percentuais.

O Banco da Inglaterra demorou, igualmente, a atuar como prestamista em última instância e prestar socorro ao Northern Rock, protagonizando à primeira corrida bancária em mais de 140 anos da história do sistema monetário inglês (The Economist, 2007), berço “da arte do banco central”. O Ato de 1998 que atribuiu independência ao Banco da Inglaterra e instituiu a manutenção da estabilidade dos preços como seu objetivo principal, manteve sua responsabilidade pela estabilidade do sistema financeiro como um todo. A legislação prevê que para garantir a estabilidade do sistema financeiro e evitar risco de crise sistêmica o Banco 
atue de forma coordenada com a Financial Service Authority, organismo que em 1997 assumiu a responsabilidade pela supervisão das instituições financeiras, bancárias e não-bancárias. Porém, não foi o que se viu em setembro de 2007.

O Northern Rock, o quinto maior banco hipotecário britânico, que acabou estatizado no dia 18 de fevereiro de 2008, enfrentou sérios problemas de liquidez não por envolvimento direto com a crise subprime americana, mas por operar com alta alavancagem, apoiado na securitização das hipotecas e no mercado interbancário. Embora a corrida dos depositantes ao Northern Rock tenha sido interrompida após o anúncio, no dia 17 de setembro de 2007, pelo ministro do Tesouro de concessão de garantia da integralidade dos depósitos, o sistema bancário inglês enfrentou fuga internacional de capital, o que contribuiu para amplificar as turbulências do mercado financeiro.

Só após essa operação de socorro ao Northern Rock é que o Banco da Inglaterra seguiu o exemplo do Fed e do BCE e injetou $£ 10$ bilhões (US\$ 20 bilhões) no mercado interbancário, que se encontrava paralisado. Após manter a taxa de juros básica inalterada em janeiro, o Banco da Inglaterra voltou, no entanto, a reduzi-la em fevereiro de 2008. Mesmo em um contexto de elevação da inflação devido à forte alta dos preços dos alimentos e dos combustíveis, em âmbito global, o comitê de política monetária (MPC) decidiu por um corte de 0,25 p.p. na taxa básica, que declinou de 5,5\% para 5,25\%. O presidente do banco central inglês, Mervyn King, admitiu em entrevista à imprensa que o MPC enfrenta um dilema e que está buscando conciliar a meta de inflação de $2 \%$ no médio prazo com a prevenção de forte desaceleração da economia. A opção pelo corte dos juros mesmo com a previsão de que a inflação atinja $3 \%$ em meados de 2008 indica que as preocupações com o crescimento e com a estabilidade do sistema financeiro falaram mais alto do que os temores de aceleração da inflação e de descumprimento da meta.

Já o BCE, embora continue mantendo a taxa juros em $4 \%$ desde março de 2007 em razões das pressões inflacionárias associados à alta nos preços dos alimentos e combustíveis, foi pródigo em injetar liquidez no sistema bancário, para evitar ameaça de risco sistêmico. No dia 9 de agosto, por exemplo, após a taxa overnigth do interbancário na área do euro ter atingido 4,6\%, ou seja, 0,6 p.p. acima da meta, em razão dos temores desencadeados pela exposição do banco francês BNP Paribas à crise subprime, o BCE surpreendeu os analistas financeiros, colocando $€ 95$ bilhões (US\$ 131 bilhões) no mercado monetário, montante bem superior ao colocado à disposição dos bancos na crise de iliquidez após os ataques do 11 de Setembro de 2001.

Desde agosto de 2007, também o Fed vem injetando dinheiro no sistema monetário local, principalmente com garantia nos créditos hipotecários. Essas intervenções têm como propósito trazer os juros dos empréstimos interbancários para mais perto da meta da taxa básica de juros. Não obstante, as taxas de juros dos mercados interbancários registraram forte volatilidade, refletindo as dificuldades de avaliar a extensão das exposições dos bancos à crise.

Porém, a partir de dezembro, após a ação coordenada, que envolveu cinco bancos centrais - Fed, BCE, Banco da Inglaterra, Banco da Suíça (SNB), Bank 
of Canada - as taxas dos mercados interbancários começaram a recuar (Gráfico 2). No dia 12, foram injetados nos diversos mercados interbancários cerca de US\$ 110 bilhões. Nesse mesmo dia, o Fed colocou à disposição do BCE e do SNB linhas de swap em moeda estrangeira, respectivamente, no montante de US\$20 bilhões e US\$ 4 bilhões. Essas operações foram realizadas com o propósito de diminuir a pressão sobre as taxas de juros interbancárias — em particular a Libor (London Interbank Offered Rate), referência internacional para empréstimos entre bancos.

Gráfico 2

Taxa do Mercado Interbancário ${ }^{1}$ e Taxas Oficiais de Juros $^{2}$ - \%

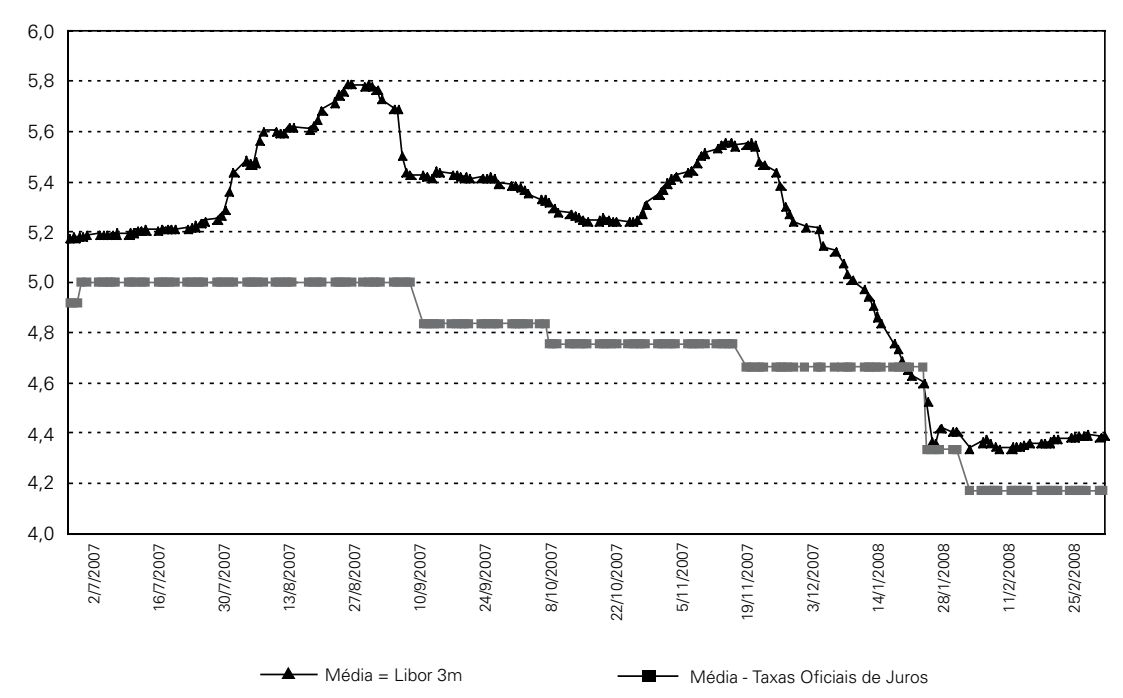

Fonte: British Bankers' Association e páginas eletrônicas dos bancos centrais.

Notas: 'Libor de três meses para dólar, euro e libra esterlina, taxa diária até o dia 4 de março de 2008; ${ }^{2}$ Metas das taxas de juros oficiais dos EUA, Área do Euro e Reino Unido.

Igualmente, o Fed anunciou a decisão de utilizar um instrumento temporário para o fornecimento de liquidez ao sistema bancário: Term Auction Facility (TAF). Mediante a realização de leilões de dinheiro, o Fed passou a conceder aos bancos empréstimos de curto prazo (acordos de compra e venda por 28 dias) com taxa de juros inferior às operações de redesconto, aceitando como garantia uma gama maior de títulos do que nas operações do mercado aberto (títulos do Tesouro e das agências federais). Desde dezembro, o Fed vem realizando leilões quinzenais, que ocorrerão enquanto for necessário para reduzir as pressões no mercado monetário.

Em 18 de dezembro, o BCE colocou $€$ 348,6 bilhões (US\$ 501,5 bilhões) por duas semanas, cobrando apenas 0,21 p.p. acima da taxa básica de $4 \%$. Com aumento da liquidez do mercado interbancário, o TED spread recuou para 1,56 p.p. contra 2,35 p.p. no dia 13 de dezembro (contra 0,35 p.p. no início de 2007). O TED spread continuou recuando até início de janeiro (0,83 p.p. no dia 11$)$, quan- 
do voltou a subir com anúncio dos balanços do quarto trimestre, atingindo 1,63 p.p. no dia 6 de março de 2008 (Gráfico 1).

A cada dia, contudo, novos fatos e rumores contribuem para ampliar o clima de desconfiança e de temor quanto à magnitude real das perdas associadas à crise das hipotecas subprime. Para acalmar os mercados, agitados com os boatos de quebra do banco de investimento Bear Stearns e evitar a espiral de deflação de ativos, no dia 11 de março de 2008 o Fed anunciou outra ação coordenada com outros bancos centrais de injeção de liquidez nos mercados interbancários. De sua parte, além de elevar a US\$100 milhões os leilões de leilões de dinheiro na modalidade $T A F$, o Fed anunciou uma nova modalidade de auxílio ao sistema bancário: Term Securities Lending Facility (TSLF). Sob essa nova modalidade, realizará empréstimos de até US\$ 200 bilhões em títulos do Tesouro contra garantia de um amplo conjunto de ativos, incluindo aqueles lastreados em hipotecas, que possuem rating AAA/Aaa. Igualmente, o Fed ampliou a linha de crédito recíproco (swap lines) para o BCE (US\$ 30 bilhões) e para o SNB (US\$ 6 bilhões).

O BCE anunciou a realização de leilões de dólares por 28 dias contra colateral denominado em euro. Na mesma data, o SNB anunciou que realizará leilão de dólares no dia 25 de março contra colaterais elegíveis e que continuará fornecendo liquidez em dólares até quando se fizer necessário. Já os bancos centrais do Canadá e Inglaterra anunciaram novas operações de recompra em março e abril, com colateral de um amplo leque de títulos de alta qualidade. No caso inglês, os recursos serão oferecidos em operações de três meses no mercado aberto. Em março de 2008 serão oferecidos $£ 10$ bilhões, enquanto o montante de abril ainda será definido. ${ }^{10}$

Em 14 de março, o Fed, por meio do conglomerado JP Morgan Chase, foi forçado a realizar uma operação de salvamento do banco de investimento Bear Stearns, diante de rumores de insolvência. ${ }^{11}$ Formalmente, o Fed está autorizado a operar apenas com os bancos comerciais (primary dealers). Por isso, houve a necessidade da intermediação do JP Morgan Chase (além de operações cruzadas nos mercados de derivativos de crédito). $\mathrm{E}$, finalmente, no dia 16 , antes da abertura dos mercados, o Fed anunciou o corte de $0,25 \%$ na taxa de redesconto (de $3,5 \%$ para $3,25 \%$ ) e a abertura de uma linha de crédito de 90 dias para os primary dealers com colateral constituído de um amplo conjunto de títulos com grau de investimento para que possam refinanciar os participantes do mercado aberto, dentre os quais os bancos de investimento.

Essas ações para reduzir o empoçamento de liquidez no interbancário e di-

\footnotetext{
${ }^{10}$ Informações obtidas nas páginas eletrônicas desses bancos centrais que divulgaram Nota para Imprensa em 11 de março de 2008.

${ }^{11}$ Os bancos centrais estão agindo como sugeriram Buiter \& Sibert (2007). Segundo esses autores, nesse novo mercado financeiro a atuação de lender of last resort dos bancos centrais tornou-se insuficiente. Devem atuar também como market maker of last resort, aceitando ativos ilíquidos como colateral de operações de recompra a fim de deter a deflação dos preços.
} 
minuir as pressões altistas sobre os juros são vistas com ceticismo pelos analistas que consideram que até todas as perdas serem anunciadas e contabilizadas pelos bancos a contração de crédito e liquidez não será resolvida. Persiste o temor de as perdas incorridas pelas instituições financeiras, sobretudo os bancos, induzir uma forte contração do crédito, com efeitos cumulativos sobre o consumo das famílias e os investimentos das empresas. Isso provocaria o desaquecimento da economia que, por sua vez, aumentaria ainda mais a fragilidade dos créditos. Esse cenário desponta no horizonte, à medida que as taxas de juros de longo prazo, incluindo as de hipotecas com juros fixos, sobem em vez de acompanhar as quedas promovidas na federal funds rate. Ademais, a elevação dos preços do petróleo e das commodities agrícolas reduz a renda real das famílias, dificultando o pagamento dos serviços das hipotecas. Nessas circunstâncias, uma política monetária agressiva pode ter efeitos limitados sobre o desempenho da economia.

\section{REFERÊNCIAS BIBLIOGRÁFICAS}

AGLIETTA, Michel (2004). Macroeconomia financeira, Vols. 1 e 2. São Paulo: Edições Loyola, 2004. BRAGA, José C. de S. \& CINTRA, Marcos A. M. (2004). Finanças dolarizadas e capital financeiro: exasperação sob comando americano, in: FIORI, José L. (Org.) O poder americano. Petrópolis: Editora Vozes, pp. 253-307.

BUITER, Willem \& SIBERT, Anne (2007). The central bank as the market maker of last resort: from lender of last resort to market maker of last resort, August $13^{\text {th }}$. Disponível em http://www.voxeu. org/.

CAGNIN, Rafael F. (2007). O mercado imobiliário e a recuperação econômica dos EUA após 2002. Dissertação de Mestrado, IE/Unicamp, Campinas.

CINTRA, Marcos A. M. \& CAGNIN, Rafael F. (2007). Evolução da estrutura e da dinâmica das finanças norte-americanas. Econômica, Rio de Janeiro, v. 9, n. 1, pp. 89-131, dezembro.

COUTINHO, Luciano \& BELLUZZO, Luiz G. M. (1996) Desenvolvimento e estabilização sob finanças globalizadas, Economia e Sociedade, n. 7. Campinas: IE/Unicamp, pp. 129-154.

ECONOMIST (The) (2007). The Bank that failed. From The Economist print edition, September $20^{\text {th }}$. Disponível em http://Economist.com.

(2008). Bank of America's big gamble: Buying Countrywide for $\$ 4$ billion. January $11^{\text {th }}$. Disponível em http://Economist.com.

FARHI, Maryse \& CINTRA, Marcos A. M. (2002). Informação dos investidores: classificação de riscos, contabilidade e conflitos de interesses, Ensaios FEE, v. 23, n. 2. Porto Alegre: Fundação de Economia e Estatística, pp. 761-786.

FENDER, Ingo \& MITCHELL, Jeanet (2005). Structured finance: complexity, risk and the use of ratings. BIS Quarterly Review, Basle: Bank for International Settlement, p. 67-79, June.

FMI - Fundo Monetário Internacional. Global Financial Stability Report, Washington, DC: International Monetary Fund, September, 2007.

GUTTMANN, Robert \& PLIHON, Dominique. Consumer debt at the center of finance-led capitalism. Paris, janeiro de 2008 (mimeo).

KREGEL, Jan (2008). Minsky's cushions of safety: Systemic risk and the crisis in the U.S. subprime mortgage market. Public Policy Brief No. 93, The Levy Economics Institute of Bard College, January.

(2007). The natural instability of financial markets. Working Paper No. 523, The Levy Economics Institute of Bard College, December.

MINSKY, Hyman P. (1986) Stabilizing an unstable economy. New Haven: Yale University Press. 
PARISI-CAPONE, Elisa. Structured finance glossary, RGE Monitor, January $7^{\text {th }} 2008$.

PARTNOY, Frank \& SKEEL Jr., David (2006). The promise and perils of credit derivatives, Working Paper $N^{\circ} 125$, University of Pennsylvania Law School, 2006. Disponível em http://lsr.nellco.org/ upenn/wps/papers/125.

ROUBINI, Nouriel (2008). The staggering costs of bailing out a financial system in crisis. RGE Monitor, March. 